\title{
COMPARATIVE EVALUATION OF KETOPROFEN CREAM WITH DICLOFENAC AND PIROXICAM CREAM IN PATIENTS WITH RHEUMATOID ARTHRITIS DISORDERS:
}

\author{
Muhammad Razi Ullah Khan ${ }^{1,2^{*}}$, Saeed Ur Rashid Nazir ${ }^{2}$, Musaddique Hussain ${ }^{3}$
}

\begin{abstract}
1.Department of Pharmacy, Superior University, Lahore, Pakistan. Lahore-54000

2.Faculty of Pharmacy, University of Sargodha, 40100, Sargodha Pakistan

3.School of Pharmacy, The University of Faisalabad, Faisalabad, Pakistan Postal Code: 38600
\end{abstract}

Submitted: $18-10-2014$

Revised: 20-11-2014

Accepted: $30-11-2014$

${ }^{*}$ Corresponding author

M. Razi Ullah Khan

Email:

raziullahpharmacist@gmail.com

\section{INTRODUCTION}

Rheumatoid arthritis is an autoimmune progressive disorder that leads to the destruction of cartridge, bone and ligaments causing deformity of joints (Wolfe and Hawley 1998). The cause of rheumatoid arthritis is unknown. It is believed that the tendency to develop rheumatoid arthritis may be genetically inherited (hereditary). Certain genes have been identified that increase the risk for rheumatoid arthritis (Pedersen et al., 2007). Non-steroidal anti-inflammatory drugs (NSAIDs) are widely used to relieve pain and inflammation in rheumatoid arthritis patients, but their use comes at the cost of toxicity, with a $2-4 \%$ annual incidence of serious gastrointestinal ulcer and complications-four times higher than in non-users (Lanas, 2009). NSAIDs have been applied topically for decades. This route possibly reduces gastrointestinal adverse reactions by maximizing local delivery and minimizing systemic toxicity (Massó González et al., 2010). Ketoprofen, diclofenac and piroxicam are the drugs included in the class of non-steroidal anti-inflammatory drugs (NSAIDs), each drug has a specific tissue distribution and pharmacodynamics (Rainsford et al., 2008). They block the inflammatory cascade and cycloxygenases (COX) by inhibiting prostaglandin and thromboxane 
production and lead to reduction in pain, fever, platelet aggregation and inflammatory response (Rao, 2008). Besides inhibiting the prostaglandin and thromboxane production, Ketoprofen also inhibit rabbit neutrophil and human lung lipoxygenase activity (Kokki 2002). NSAIDs like ketoprofen, diclofenac and piroxicam are generally indicated for symptomatic relief of rheumatoid arthritis, osteoarthritis (Towheed 2006), inflammatory arthropathies (Ankylosing spondylitis, psoriatic arthritis), gout (Massey et al., 2010), metastatic bone pain, post operative pain, dysmenorrhoea (Brunton, et al.,2006), migraine and headache. The use of oral preparations of NSAIDs increase the risk of gastrointestinal and cardiovascular complications compared with non NSAIDs users (Aronson, 2005). Reduction of adverse drug reactions associated with the use of topical preparations of NSAIDs is being well considered to obtain high patient compliance and drug therapy efficacy (Bjorkman, 1999). Substantial data suggests that topical NSAIDs have pain-relieving properties in rheumatoid arthritis disease. An important sign of the increasing importance of using topical medication is that the European League against Rheumatism and the International Osteoarthritis Research Society state that topical NSAIDs are preferred over oral NSAIDs for mild-to-moderate hand and knee osteoarthritis, in patients with sensitivity to oral compounds (Altman and Barkin, 2009). In addition, the UK NICE guidelines for knee and hand osteoarthritis recommend use of paracetamol and/or topical NSAIDs over oral NSAIDs, COX2 inhibitors, and opioids (Conaghan, et al., 2008).

\section{MATERIAL AND METHODS}

Human volunteers: 125; Gender: Male and Female; Age: 40-70 years; Cream Formulations: Ketoprofen cream (1\% w/w) Nazir et al., 2013); Diclofenac cream (1\% $\mathrm{w} / \mathrm{w})$; Pioxicam cream $(0.5 \% \mathrm{w} / \mathrm{w})$

\section{Methods}

This is a single blind, randomized comparative trial conducted at three different locations: Bajwa Trauma Centre, Sargodha, Pakistan; Amin Orthopedic Centre, Sargodha, Pakistan; National Hospital, Faisalabad,
Pakistan. One hundred and twenty five volunteers were divided into three groups receiving ketoprofen cream, diclofenac cream and/or piroxicam cream. The volunteers were given written instructions to apply the cream regularly on affected area in a dose of 4 inches 3-4 times a day up to 14 days. Volunteers both (males and non- pregnant females) between the ages of 40-70 suffered from acute rheumatoid arthritis were included in this study.

\section{Inclusion criteria for study}

The volunteer is $40-70$ years of age; The volunteer is diagnosed with uncomplicated acute rheumatoid arthritis; The site of injury is accessible to the volunteer so that he/she can apply the study medication himself/herself; The volunteer must meet the pain entry criteria; The volunteer is willing to discontinue use of any pain medication not provided as a part of study

\section{Exclusion criteria for study}

The volunteer has active skin lesions at the intended site of application of study medication. Skin lesions include open wound, rash, papules, vesicles and erythema associated with the site of injury. The volunteer has used any form of opoids since the time of injury. The volunteer has taken any form of steroids within 30 days prior to enter into study. The volunteer has done nonpharmacological treatment of injury. The volunteer has experienced any kind of allergy to ketoprofen, diclofenac or piroxicam. The volunteer has participated in an investigational drug study or received an investigational drug within a period of 30 days prior receiving the study mediation. Recent injuries sustained within $4 \mathrm{~h}$ (not requiring surgical treatment) were included under "acute" category. Written informed consent was obtained prior to enrollment of patients in the study. The patients were evaluated before initiation of therapy and then at day 1 , day 4, day 8 and day 14 of the therapy for the following parameters.

Pain intensity on a $10 \mathrm{~cm}$ visual analogue scale ( 0 -worst ever, 10 -best ever); pain at rest, passive movement, palpation and isometric contraction on a 4 point scale ( 0 -absent, 1 -mild, 
Table I. Patient demographics.

\begin{tabular}{clccc}
\hline Parameters & Ketoprofen cream & Diclofenac cream & Piroxicam cream \\
\hline Total no. of patients & 45 & 35 & & 30 \\
Sex: & & & & \\
Male & 22 & 15 & 11 \\
Female & 23 & 20 & 19 \\
\hline
\end{tabular}

Table II. Comparitive evaluation of different creams over 14 days period

\begin{tabular}{|c|c|c|c|c|c|c|c|c|c|c|c|c|}
\hline \multirow[t]{2}{*}{$\begin{array}{l}\text { Day } \\
\text { characteristics }\end{array}$} & \multicolumn{4}{|c|}{$\begin{array}{l}\text { Ketopofen cream } \\
(\mathrm{n}=45)\end{array}$} & \multicolumn{4}{|c|}{$\begin{array}{c}\text { Diclofenac cream } \\
(\mathrm{n}=35)\end{array}$} & \multicolumn{4}{|c|}{$\begin{array}{c}\text { Piroxicam cream } \\
(\mathrm{n}=30)\end{array}$} \\
\hline & 1 & 4 & 8 & 14 & 1 & 4 & 8 & 14 & 1 & 4 & 8 & 14 \\
\hline $\begin{array}{l}\text { Pain intensity on } \\
\text { VAS }(\mathrm{cm})\end{array}$ & 4.15 & 6.29 & 7.55 & 9.77 & 3.75 & 4.88 & 6.29 & 8.01 & 3.99 & 5.01 & 7.0 & 8.44 \\
\hline Pain at rest & 2.1 & 1.8 & 0.7 & 0.1 & 2.1 & 1.9 & 1.2 & 0.9 & 2.1 & 1.8 & 1.2 & 0.8 \\
\hline $\begin{array}{l}\text { Pain on passive } \\
\text { Motion }\end{array}$ & 2.3 & 1.9 & 0.9 & 0.2 & 2.3 & 2.0 & 1.4 & 0.9 & 2.3 & 1.9 & 1.3 & 0.8 \\
\hline Pain on palpation & 2.7 & 2.1 & 1.2 & 0.5 & 2.7 & 2.2 & 1.7 & 1.0 & 2.7 & 2.1 & 1.6 & 0.9 \\
\hline $\begin{array}{l}\text { Pain on isometric } \\
\text { Contraction }\end{array}$ & 3.0 & 2.4 & 1.5 & 0.6 & 3.0 & 2.6 & 1.9 & 1.2 & 3.0 & 2.5 & 1.6 & 1.0 \\
\hline Tenderness & 2.5 & 1.8 & 0.9 & 0.2 & 2.5 & 2.0 & 1.3 & 0.8 & 2.5 & 1.9 & 1.1 & 0.6 \\
\hline Swelling & 3.0 & 2.1 & 1.4 & 0.3 & 3.0 & 2.4 & 1.8 & 1.0 & 3.0 & 2.2 & 1.5 & 0.8 \\
\hline $\begin{array}{l}\text { Functional } \\
\text { Impairment }\end{array}$ & 3.5 & 2.6 & 1.6 & 0.5 & 3.5 & 2.9 & 2.0 & 1.1 & 3.5 & 2.8 & 1.9 & 0.9 \\
\hline
\end{tabular}

2-moderate, 3-severe); Tenderness on a 4 point scale (0-not tender, 1-tender, 2-winced, 3withdrew); Swelling on a 4 point scale (0absent, 1-mild, 2-moderate, 3-severe); Functional impairment on 5 point scale: (onone, 1 mild, 2 moderate, 3 marked and 4 severe); Paracetamol was given as rescue drug in case the pain relief by topical formulations was inadequate. The amount of paracetamol intake was recorded as indirect measurement of effectiveness of the trail drugs.

\section{RESULTS AND DISCUSSION}

A total of 125 patients of aged between 40-70 years were enrolled in this study. However 15 patients were lost to follow up and only 110 patients were evaluated. A total of 45 patients received ketoprofen cream, 35 received diclofenac cream and 30 received piroxicam cream. The ratio of males to females in the study was 19:25 (48/62). The patient's demographics of all three groups were comparable (Table I).
Within the group all the three groups had improvement in the various parameters studied (onset of pain; pain intensity on a $10 \mathrm{~cm}$ VAS; pain at rest, passive movement; palpation and isometric contraction; swelling; tenderness: and functional impairment). This improvement was statistically significant when compared at the beginning and end of the therapy. However, over the study period of 14 days there was no significant change in the paracetamol intake in all the three groups.

The onset of pain relief was observed between 1-2 hours. In some cases the onset of pain relief was quite delayed but there was not much difference between groups. The between group analysis showed that treatment with ketoprofen cream was significantly more effective than diclofenac cream and clinically better than piroxicam cream. The pain intensity on $10 \mathrm{~cm}$ visual analogue scale was best ever 98\% with ketoprofen cream group, $80 \%$ with diclofenac cream and $84 \%$ with piroxicam cream group at the end of therapy. 


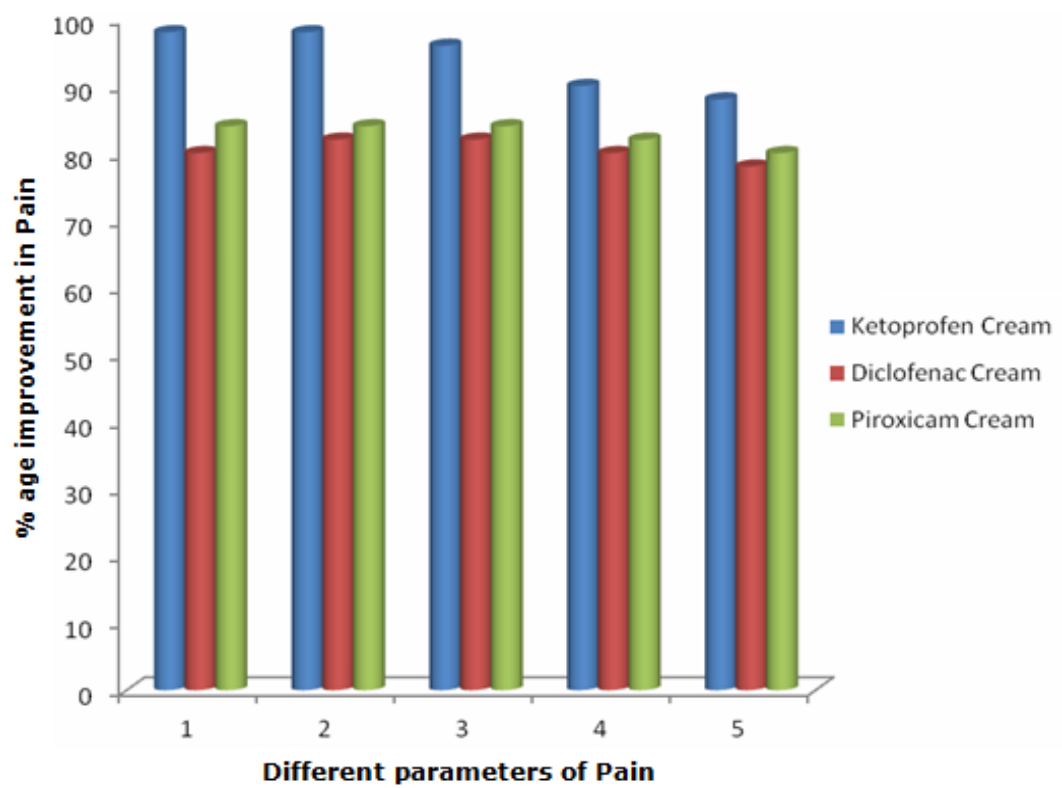

Figure 1: Improvement in pain over 14 days study period

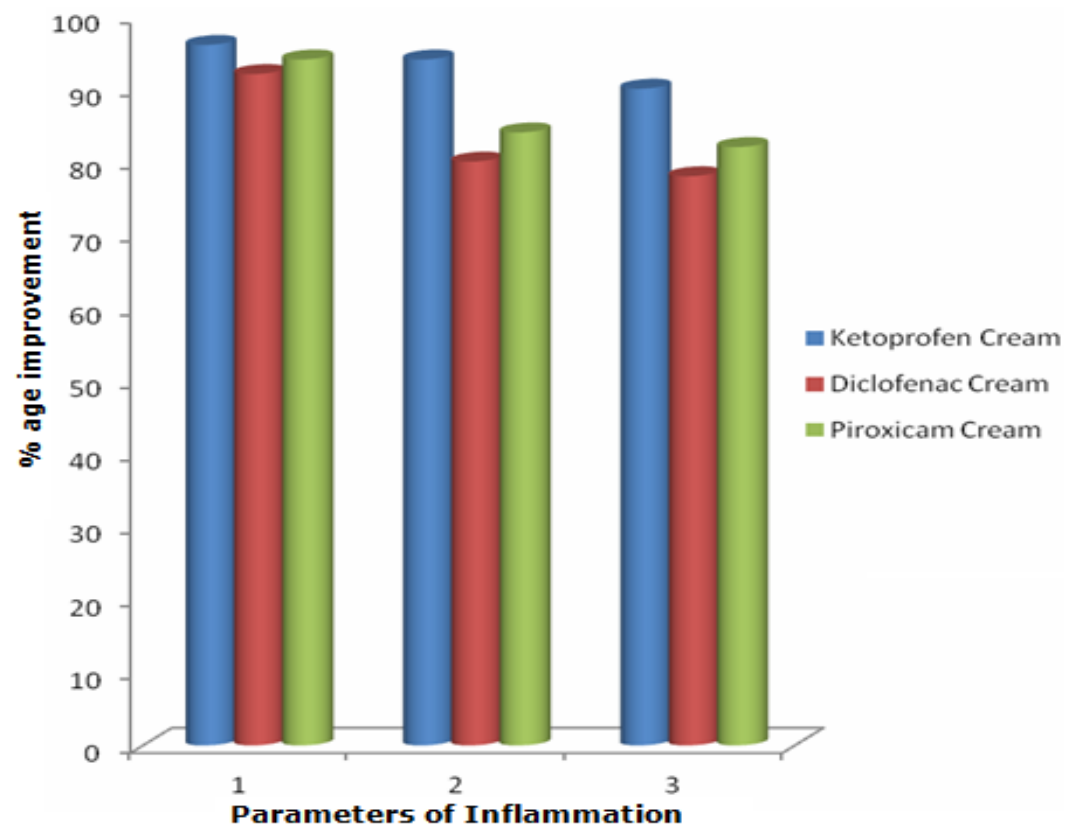

Figure II. Improvement in inflammation over 14 days study period

The pain intensity mean score of $9.77 \mathrm{~cm}$ (when assessed on 0-10 cm VAS) for ketoprofen cream was statistically more significant $(\mathrm{p}<0.01)$ than diclofenac and piroxicam cream whose mean scores were 8.01and 8.44 respectively indicated by number 1 on $\mathrm{x}$-axis in figure 1.
At day 14, 98\% improvement was seen in patients with pain at rest with ketoprofen cream, $82 \%$ with diclofenac cream and $84 \%$ with piroxicam cream. pain at passive motion was improved up to $96 \%$ with ketoprofen cream than $82 \%$ and $84 \%$ with diclofenac and piroxicam groups respectively. Pain at 
palpitation and isometric contraction was improved upto $90 \%$ and $88 \%$ with ketoprofen cream group respectively, $80 \%$ and $78 \%$ with diclofenac cream group respectively and $82 \%$ and $80 \%$ with piroxicam cream respectively as shown by number $2,3,4$ and 5 on $\mathrm{x}$-axis in figure I.

Clinically tenderness was absent up to $96 \%$ in ketoprofen cream group, $92 \%$ in diclofenac cream group and $94 \%$ in piroxicam cream group representated by number1 on $\mathrm{x}$ axis in figure ii. Absence in swelling was observed $94 \%$ with ketoprofen cream group as compared to $80 \%$ and $84 \%$ with diclofenac and piroxicam group at the end of therapy. Functional improvement was seen $90 \%$ with ketoprofen cream group than $78 \%$ and $82 \%$ with diclofenac and piroxicam cream groups respectively as shown in figure II.

No statistically significant difference was observed in the paracetamol intake between the three groups.

\section{CONCLUSIONS}

Ketoprofen, diclofenac and piroxicam all three are nsaids that exhibit analgesic, antipyretic and anti-inflammatory activities. From the above results it can be concluded that on day 14 ketoprofen cream was statistically better $(p<0.01)$ in reducing pain, tenderness, and swelling and improves the functional ability than diclofenac cream. Piroxicam cream rated better $(p<0.05)$ in these parameter as compared to diclofenac cream.

\section{ACKNOWLEDGMENT}

The authors are very thankful to School of Pharmacy, The University of Faisalabad, Faisalabad for supporting this research.

\section{REFERENCES}

Altman R., Barkin RL. 2009. Topical therapy for osteoarthritis: clinical and pharmacologic perspectives. Postgrad Med. 121(2):139- 147.

Aronson JK. editor. 2005. Meyler's Side Effects of Drugs- The International Encyclopedia of Adverse Drug Reactions and Interactions. 15th ed. Amsterdam, The Netherlands: Elsevier Science;
Bjorkman DJ., 1999. Current Status of Non Steroidal Anti inflammatory Drugs Use in United States: Risk factors and Frequency of Complications. Am.J.Med, 107,35-85.

Brunton LL., Lazo JS., Parker KL., 2006. Goodman and Gilman's The Pharmacological Basis of Therapeutics. 11th ed. New York, NY: McGrawHill;

Conaghan PG., Dickson J., Grant RL. 2008; Guideline Development Group. Care and management of osteoarthritis in adults: summary of NICE guidance. BMJ. 336(7642):502-503.

Kokki H., Karvinem M., Jekunen A. 2002. Diffusion of Ketoprofen into the Cerebrospinal Fluid of Young Children. Paediatr Anaesth 12: 313-316.

Lanas A., 2009. Nonsteridal antiinflammatory drugs and cyclooxygenase inhibition in the gastrointestinal tract: a trip from peptic ulcer to colon cancer. Am J Med Sci 338:96-106.

Massey T., Derry S., Moore RA., McQuay HJ., 2010. Topical NSAIDs for acute pain in adults. Cochrane Database Syst Rev. 6:CD007402.

Massó González EL., Patrignani P., Tacconelli S., García Rodríguez L., 2010. Variability among nonsteroidal antiinflammatory drugs in risk of upper gastrointestinal bleeding. Artbritis Rheum 62:1592-1601.

Nazir SU., et al. 2013. Formulation Development, Evaluation and Antiinflammatory effects of Ketoprofen cream on Rheumatoid Arthritis Patients. Ijcls ;3:132-136.

Pedersen M., Jacobsen S., Garred P., Madsen HO., Klarlund M., et al., 2007. Strong combined gene-environment effects in anti-cyclic citrullinated peptide-positive rheumatoid arthritis: a nationwide case-control study in Denmark. Arthritis Rheum 56: 1446-1453. doi: 10.1002/art.22597

Rainsford KD., Kean WF., Ehrlich GE. 2008. Review of the pharmaceutical properties and clinical effects of the topical NSAID 
formulations. Curr Med Res Opin. 24(10):2967-2992.

Rao P., Knaus EE., 2008. Evolution of nonsteroidal anti-inflammatory drugs (NSAIDs): cyclooxygenase (COX) inhibition and beyond. I Pharm Pharm Sci. 11(2):81s-110s.

Towheed TE., 2006. Pennsaid therapy for osteoarthritis of the knee: a systematic review and metaanalysis of randomized controlled trials J Rheumatol 33(3):567573.

Wolfe F., Hawley DJ., 1998 The longterm outcomes of rheumatoid arthritis: Work disability: a prospective 18 year study of 823 patients. J Rheumatol 25: 2108-2117. 